\title{
Ángel Crespo, La vida plural de Fernando Pessoa, Barcelona, Seix Barral. 2007, 414 pp.
}

Quienes hayan tenido, alguna vez, el interés de adentrarse en la interesante bibliografía de Ángel Crespo habrán, sin duda, observado que sintió una verdadera debilidad por la obra de Fernando Pessoa. En sus diarios, intitulados Los trabajos del espíritu, se evidencia que Ángel Crespo, además de ser uno de los poetas clave de la segunda mitad del siglo xx en España, poseía una sensibilidad no muy habitual hacia otras literaturas. En especial, hacia la portuguesa, tan cercana y a la vez tan lejana de la española, históricamente. La labor filológica, a la que Crespo se dedicó con ahínco, está jalonada no sólo de obras propias sino de traducciones de primer orden, las cuales no dudamos en catalogar de incomparables en el ámbito hispánico.

Por citar un ejemplo emblemático, recordemos la traducción del pessoano Libro del desasosiego. Puede afirmarse sin atisbo alguno de equivocarnos que Ángel Crespo fue el mayor admirador, conocedor e introductor de la vida y obra de Fernando Pessoa en España. Las ingentes lecturas, los viajes a Portugal junto a su esposa, doña Pilar Gómez Bedate, un consiguiente conocimiento del portugués y de la literatura portuguesa, junto con los lazos culturales entre sus amistades hispano-lusas, convirtieron a Crespo en uno de los escritores españoles con mejor criterio para acercarse a la obra pessoana. Este interés -y vía de conocimiento- se desarrolló a lo largo de su existencia, en la que el rigor filológico fue una constante. Fruto de ello apareció a finales de los años ochenta, cuando Ángel Crespo se hallaba de nuevo instalado en España, a su vuelta de Puerto Rico, el presente ensayo, La vida plural de Fernando Pessoa.

El propio título nos desvela que no se va a tratar de una biografía al uso, plagada de datos cronológicos o bibliográficos. La generosidad del Crespo humanista brilla como nunca y se traslada a las páginas del libro, de donde el lector emerge habiendo aprendido de su sabiduría las claves fundamentales de la vida, pero también de la obra, de Fernando Pessoa. La biografía la forman veintidós capítulos -más una bibliografía-, los cuales se estructuran lógicamente al hilo de la evolución vital, digamos que histórica, de Fernando Pessoa, quien, como afirma el propio Crespo en el prefacio, llegó a ser definido como "el hombre que nunca existió". Y si mérito tiene evidenciar con datos contrastados que, como en cualquier vida, hubo hechos reseñables, que permiten hacerse una idea exacta y real de la existencia lisboeta de Pessoa, entonces con mayor razón alabaremos las páginas dedicadas a aclarar los a veces intrincados caminos de su periplo vital y poético. Ambas, vida y obra, se van conjugando a lo largo del libro, pero no únicamente desde una perspectiva externa del hecho literario sino también desde un punto de vista radicalmente interno.

No olvida, sin embargo, Crespo la repercusión de la obra pessoana en la sociedad lisboeta o la realidad histórica portuguesa donde se halla inmerso ni, por supuesto, la propia peripecia vital del artista. De este modo, en los primeros capítulos, a través de cartas y escritos del autor, libros o noticias de biografías anteriores, Ángel Crespo va tejiendo, de forma apasionante, el relato de la evolución del vate portugués, desde sus años de infancia. Llama la atención, 
por ejemplo, que, durante dichos años, se traslade a Durban, ciudad de la colonia británica de Natal, junto a su familia, aunque, como nos recuerda Crespo, "su patria no dejó de ser nunca la lengua portuguesa". El autor continúa desgranando sus primeras influencias, las peculiaridades familiares, hasta llegar a sus primeros pasos literarios, es decir cuando se crea el grupo de la revista Orpheu y la invención singular de los poetas heterónimos. Aquellos que en alguna ocasión manifestaron que Pessoa no tenía biografía, quizá lo hicieron perdidos en el laberinto de sus heterónimos, pero también en el de su propia vida, repleta de fracasos en lo profesional y en lo personal. Ahí radica uno de los principales méritos de la presente biografía. En palabras de Crespo, "Si su vida fue plural, no lo fue únicamente debido a las intensísimas que vivieron sus heterónimos, éstos sí, en el reino de lo imaginario, sino también porque el poeta vivió al mismo tiempo la vida ideal del escritor ortónimo, que equivale a la de bastantes más escritores que un solo poeta, y la del inteligente, aunque fracasado por falta de medios materiales, hombre de negocios." Y es que, de hecho, buena parte de los capítulos iniciales del libro está dedicada a la gestación de los heterónimos y a su inevitable imbricación en la biografía de Pessoa.

Como Crespo expone pacientemente, debido a los heterónimos, hay constantes interferencias pero también distanciamientos, los cuales acaban por conformar una relación prismática en torno a su propio creador. En la primera parte del volumen, se asiste a la génesis de sus heterónimos más importantes: Alberto Caeiro, Álvaro de Campos y Ricardo Reis, que irán construyendo su obra autónomamente a la par que la biografía avance. Estarán presentes en los aspectos vitales y literarios más relevantes del poeta, como en la gestación de la revista Orpheu, a la que Crespo le dedica algunas de las mejores páginas, en especial a su relación con el poeta Mario de Sá-Carneiro. En especial, destaca por lo trágico y revelador, la relación epistolar entre Sá-Carneiro y Pessoa en los meses previos a la desesperada muerte de aquél. Destacan también, por otro lado, los aspectos políticos: la preocupación de Pessoa por la situación políticosocial portuguesa, el sebastianismo y todos los postulados que acaban convergiendo en su controvertida obra Interregno. En ella, Pessoa, harto de la incompetencia política de los partidos tradicionales, justifica la dictadura como un mal temporal, pero sin que sus postulados puedan definirse como fascistas.

Ángel Crespo disecciona magistralmente tanto los fundamentos y la lógica de la política pessoana como su verdadera contextualización histórica. Es el auténtico hilo conductor de este estudio: ofrecer una panorámica integral del hombre Pessoa, sin renunciar a nada. El lector podrá comprender mejor al Pessoa poeta si descubre sus intereses políticos, filosóficos o morales, no exclusivamente estéticos o literarios. Y ello incluye todas las facetas del hombre. Tanto es así que, en determinadas ocasiones, el lector se erige en espectador privilegiado de un Pessoa muy íntimo, desconocido para muchos. Sus rutas vitales se revelan en el libro: los cafés que frecuentaba, cómo le veían allí, qué solía hacer en el trabajo y fuera de él, qué tipo de hombre era; en definitiva, todos aquellos elementos que tiran por tierra la mencionada opinión de que era 
un gran desconocido. En este sentido, lo que más puede sorprender es la investigación dedicada a los amoríos del poeta.

Pessoa se enamoró de una joven lisboeta llamada Ofelia Queirós, aunque las dificultades económicas le impidieron quizá formar con ella una familia, por lo que el noviazgo no prosperó. Sin embargo, del mismo se conservaron cartas y comentarios de la propia Ofelia, que Crespo utiliza para echar luz sobre la sexualidad del portugués y de paso sobre otros aspectos personales, que nos acaban remitiendo a su obra y que, sobre todo, informan sobre su personalidad. Asistimos a momentos de gran ilusión y de excitación del poeta, combinados con otros de amargura y abatimiento, que llevan a Pessoa a hacerle pensar que estaría mejor recluido en un sanatorio. Otro de los temas cruciales, para la comprensión de la figura del portugués, es el del ocultismo. Pessoa se interesó desde joven por la teosofía y las llamadas ciencias ocultas, y esa afición tiene un lugar en su obra, como apunta el autor de Una lengua emerge. En el capítulo viii, Crespo hace hincapié en un hecho a veces soslayado por la crítica: "a Fernando le venía de muy lejos su interés por lo misterioso y por los conocimientos esotéricos, y entre sus mejores amigos se contaban varios estudiosos de las ciencias ocultas."

Si se ahonda en esta vertiente pessoana se aclaran ciertos pasajes de su poesía y se perfila con más claridad la figura general del poeta. En este sentido, llama la atención la relación entre el poeta y uno de los personajes británicos más misteriosos del siglo xx, Aleister Crowley, fundador de la secta ocultista Golden Down. Pessoa concebía la poesía como un camino iniciático, especialmente al final de su trayectoria, cuando más atención presta al ocultismo y a la búsqueda de un conocimiento aún no revelado. Es en extremo pintoresca la recreación, elaborada por Crespo, de la cita lisboeta entre ambos personajes, en un pasaje que roza lo novelesco en su estado puro, con un Pessoa vacilante, que espera en el puerto a un extraño individuo a quien no conoce personalmente. Aunque anecdótico, este episodio no tiene nada de incongruente, ya que es, justamente, hacia el final de la vida de Pessoa, cuando se desvelan ciertas claves medulares de su obra y de su vida. Ángel Crespo ha sabido aupar al lector hasta los capítulos finales del libro. En ellos desentraña, a modo de perspectiva, los verdaderos resortes de una vida compleja y de unas aspiraciones literarias y culturales de gran calado. Es justo en esta época final, en la que Pessoa no llega a la cincuentena, en la que Pessoa produce más obras ortónimas y en la que ve con claridad la pervivencia de su obra. Se trata de unos capítulos fundamentales porque echan luz sobre el resto.

Vemos como el lisboeta se aleja de sus postulados de Interregno y comprende que la dictadura no abocará a Portugal al ansiado Quinto Imperio, que el lugar hegemónico que la cultura portuguesa debería alcanzar, el sebastianismo, en suma, no provendrá de Salazar. La regeneración nacional que encerraba el mito del sebastianismo no llegaría de manos de éste y Pessoa veía como Portugal iba a continuar sin la necesaria orientación política y social. De hecho, la obra de Pessoa no puede entenderse en absoluto sin el desarrollo de sus ideas políticas y su espiritualidad. Es lo que Crespo consigue en la parte final de su ensayo biográfico. Sirva como ejemplo, la imagen que el humanista 
español recreó del Pessoa último, a poco menos de un mes de vida: "Su salud se resentía cada vez más pero él se empeñaba en mantener su ritmo de vida habitual. Durante el día, pasaba unas horas en las oficinas comerciales despachando correspondencia, se paseaba por la Baixa, comía en cualquier parte e iba de vez en cuando a las tabernas y a los cafés acostumbrados, preferentemente al Martinho da Arcada. Por la noche, se encerraba en su casa y bebía, tal vez en busca de esa "asombrosa" lucidez que produce a veces el hacerlo en exceso. Allí, en el secreto de su aislamiento, debía de seguir pasando revista a su vida, recordando y, sobre todo, -y de ello dan fe sus poemas de entonces-, lamentándose de sus carencias y de sus fracasos, pero consolándose con la realidad de una obra que sabía imperecedera."

Juan Carlos Merchán Ruiz 